\title{
The Frankfurt Ebola patient
}

\section{Der Frankfurter Ebola-Patient}

Authors

Affiliations
T. J. Vogl', S. Martin ${ }^{1}$, H. R. Brodt' ${ }^{2}$, O. Keppler ${ }^{3}$, K. Zacharowski ${ }^{4}$, T. Wolf ${ }^{2}$

1 Department of Diagnostic and Interventional Radiology, University Hospital Frankfurt, Germany

2 Department of Medicine II, Infectiology, University Hospital Frankfurt, Germany

3 Institute of Medical Virology, University Hospital of Frankfurt, Germany

${ }^{4}$ Department of Anesthesiology, Intensive Medicine and Pain Therapy, University Hospital Frankfurt, Germany
Key words

- thorax

radiography

- infection

- Ebola received 15.1.2015

accepted 25.4.2015

\section{Bibliography}

DOI http://dx.doi.org/

10.1055/s-0035-1553130

Published online: 19.6.2015

Fortschr Röntgenstr 2015; 187 :

771-776 @ Georg Thieme

Verlag KG Stuttgart · New York .

ISSN 1438-9029

\section{Correspondence}

\section{Prof. Thomas J. Vogl}

Institut für Diagnostische und Interventionelle Radiologie,

J. W. Goethe-Universität

Frankfurt

Theodor-Stern Kai 7

60596 Frankfurt

Germany

Tel.: ++49/69/63017277

Fax: ++49/69/63017258

T.vogl@em.uni-frankfurt.de

\section{Abstract \\ $\nabla$}

Since the Ebola virus was discovered in 1976, the largest outbreak to date is the ongoing epidemic in West Africa based on the number of cases. The number of infected people is high among aid workers, some of whom have been treated at intensive care units in specialized centers in Europe and the USA. A 38-year-old patient who got infected with the Ebola virus was treated in a special isolation ward at the Frankfurt University Hospital from $10 / 3 / 14$ to $11 / 19 / 14$. During intensive care of the patient, X-rays were essential for control of the cardiopulmonary system and for follow-up. Special guidelines had to be considered for performing X-rays due to the risk of transmitting the virus. These are presented and discussed in the following.

Key Points:

- Chest radiographs are essential in the intensive care monitoring of Ebola patients.

- Chest radiographs help to assess the extent of pulmonary edema and capillary leak syndrome.

- With careful observance of hygiene guidelines, he risk of transmission can be virtually eliminated.

Citation Format:

- Vogl T J, Martin S, Brodt H R et al. The Frankfurt Ebola patient. Fortschr Röntgenstr 2015; 187: 771-776

\section{Zusammenfassung \\ $\nabla$}

Die Ebola-Epidemie in Westafrika ist gemessen an den Fallzahlen der größte Ausbruch dieser Erkrankung seit ihrer Entdeckung im Jahre 1976. Unter den Entwicklungshelfern ist die Zahl der Infektionsfälle hoch, von denen einige in spezialisierten Zentren in Europa und den USA intensivmedi- zinisch betreut wurden. Ein 38-jähriger an Ebola erkrankter Patient wurde vom 03. Oktober bis 19. November 2014 am Universitätsklinikum Frankfurt auf einer Sonderisolierstation behandelt. Bei der intensivmedizinischen Versorgung des Patienten waren Röntgenaufnahmen zur Kontrolle des kardiopulmonalen Systems und zur Verlaufskontrolle unerlässlich. Für die Anfertigung dieser Röntgenaufnahmen mussten aufgrund der Gefahr einer Übertragung spezielle Richtlinien beachtet werden, die im Folgenden vorgestellt und diskutiert werden.

\section{Introduction \\ $\checkmark$}

The outbreak of the Ebola virus in West Africa is the largest epidemic of this type to date. The virus is typically transmitted via the mucous membranes and the onset occurs after an incubation period of 3 to 21 days [1]. The clinical symptoms tend to be nonspecific initially and are expressed as fever and physical weakness. Severe vomiting and diarrhea subsequently lead to a substantial loss of fluid in the patient [2-4]. In some cases the disease culminates in capillary leak syndrome (9th14th day of the disease) that is characterized by significant fluid shift into the interstitium and can be associated with pulmonary edema, pleural effusion, or ascites $[5,6]$. The mortality rate of the current epidemic is approximately $70 \%$ [7]. In particular, medical personnel are at increased risk of infection when treating patients and must take appropriate precautionary measures. In addition, it must be ensured that materials exiting the isolation ward do not allow any pathogens to escape. 


\section{Patient care at the Frankfurt University Hospital} $\nabla$

The Frankfurt University Hospital is one of seven treatment centers for highly contagious, life-threatening diseases in Germany. The special isolation ward is in a separate building that can only be reached via special chambers. Medical personnel must wear certified protective suits and HEPAfiltered respirators to enter the isolation area. Protective equipment is put on and taken off by staff who also wear protective clothing.

\section{Radiology in the isolation ward}

$\nabla$

To minimize the risk of transmission of an Ebola infection, the following procedure for handling X-ray cassettes in the special isolation ward has been established:

A mobile X-ray unit (AMX-4, GE Healthcare Little Chalfont, Great Britain) is currently in use at the special isolation ward ( $\bullet$ Fig. 1, 2). Imaging plates with a size of $35 \times 43 \mathrm{~cm}$ (Fujifilm, Tokyo, Japan) are used for this device. Before the radiographer enters the chamber, the X-ray cassette is packaged in two protective covers and each cover is sealed in the opposite direction with tape ( $\bullet$ Fig.3). After image acquisition, the covered X-ray cassette is wiped with disinfectant on a disposable cloth (Perform 3\%, Schülke, Nordersted, Germany; contact time $15 \mathrm{~min}$ ) ( $\bullet$ Fig.4). Employees and the X-ray cassette are decontaminated in the chamber in compliance with the usual contact times ( $\bullet$ Fig. 5 ). The first protective cover is then removed, handed to a colleague in the clean chamber area, and wiped with disinfectant again (Incidin plus $2 \%$, Ecolab, St. Paul, USA; contact time $15 \mathrm{~min}$ ). The inner protective sleeve is then unwrapped and handed to external staff so that the X-ray cassette can be removed. Once the uncovered X-ray cassette has been wiped with disinfectant again, it is transported to the central institute so that the imaging plate can be read out. The covers are treated with an autoclave and properly disposed of (in accordance with Waste Code 180103 of the German Federal Working Group on Waste) [8]. — Table 1 summarizes the individual disinfection steps again. No employees were infected during treatment of the Ebola patient.

\section{Diagnostic radiology for the Ebola patient \\ $\nabla$}

The high loss of fluid caused by the increased permeability of the capillaries with leakage of plasma and plasma proteins into the interstitium necessitates intensive care of the patient. The extent of the pulmonary (vascular) leak and the pleural effusions is monitored with regular chest X-rays. Moreover, the position of materials introduced during the course of intensive care is monitored.

In our case, the patient, a 38-year-old pediatrician from Uganda, developed acute fever and diarrhea on September 28, 2014 and tested positive for Ebola the same day (day 1 of disease) [9]. On day 6 after disease onset, the patient arrived at the Frankfurt University Hospital. Immediately after the arrival of the patient at the isolation ward, the first chest $\mathrm{X}$-ray was taken with the patent lying down ( $\bullet$ Fig. 6 ). Initial pulmonary edema and left-sided pleural effusion were seen. On the 9th day of the disease, radiology showed an in-

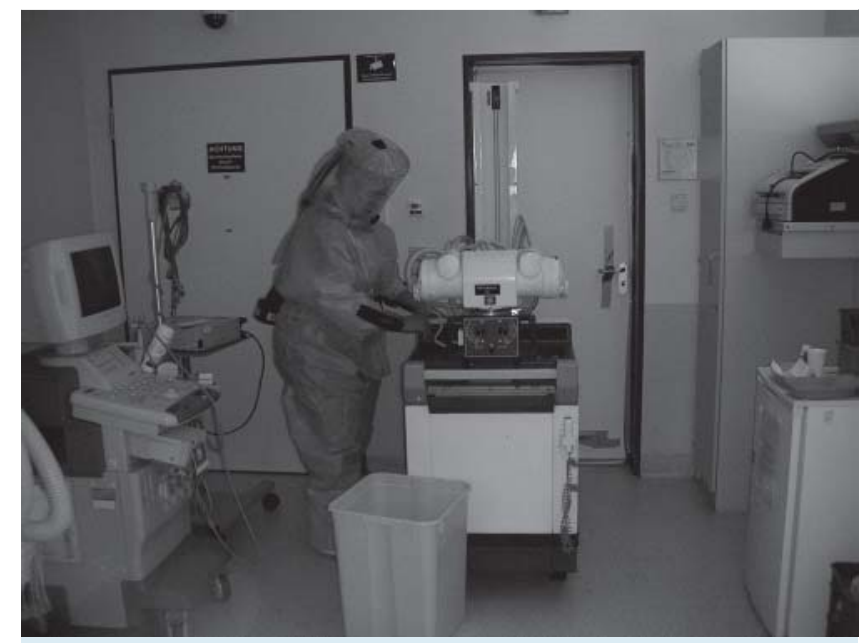

Fig. 1 X-ray unit (GE AMX-4).

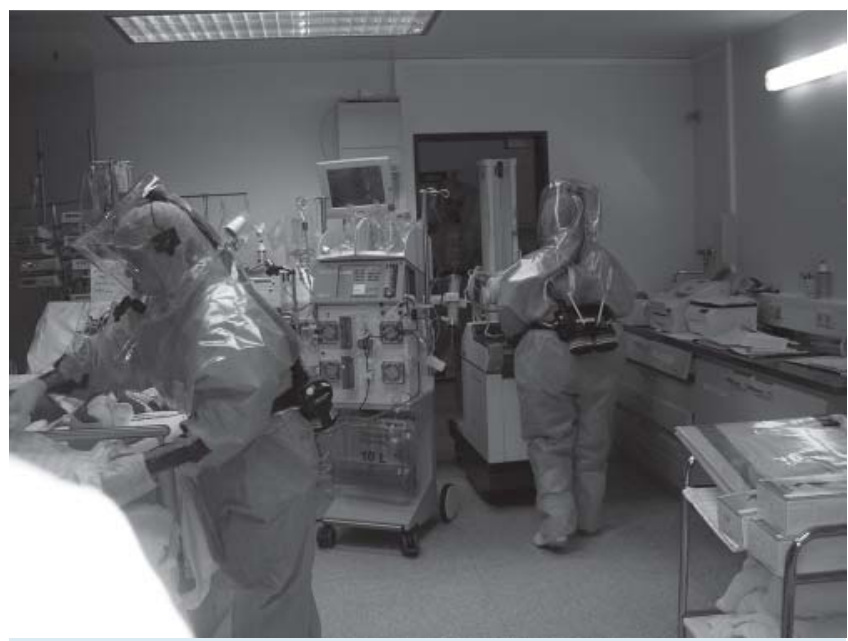

Fig. 2 Special isolation ward during preparations for X-ray of the patient.

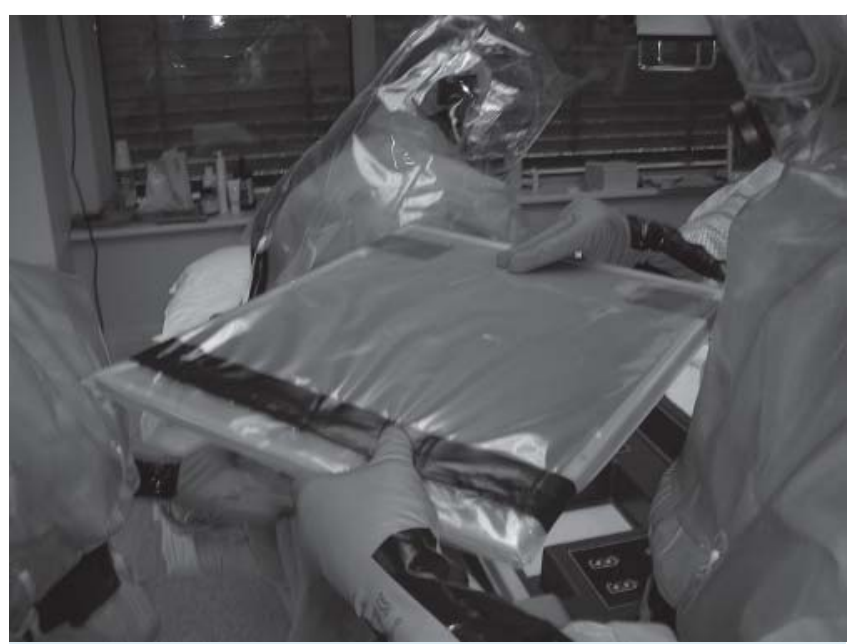

Fig. 3 The X-ray cassette is wrapped in two protective covers running in opposite directions and is sealed with tape.

crease in the pulmonary edema, and pleural effusions on both sides were diagnosed. This state was accompanied by 
Table 1 Overview of the individual steps for disinfecting the X-ray cassette.

\begin{tabular}{|c|c|c|c|c|}
\hline disinfection step & location & measure & disinfection medium & protective covers \\
\hline step 1 & isolation room & disinfection by spraying and wiping & perform $3 \%$ & 2 \\
\hline step 2 & decontamination chamber & decontamination & & 2 \\
\hline step 3 & clean chamber area & disinfection by wiping & incidin $2 \%$ & 1 \\
\hline step 4 & outside area & transfer of the cassette & & none \\
\hline
\end{tabular}

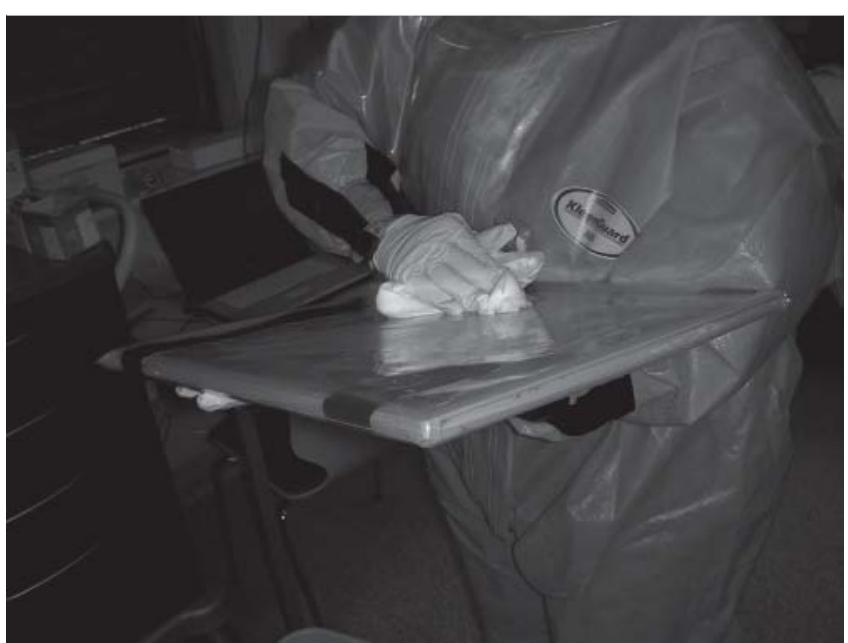

Fig. 4 First disinfection by wiping in the isolation room.

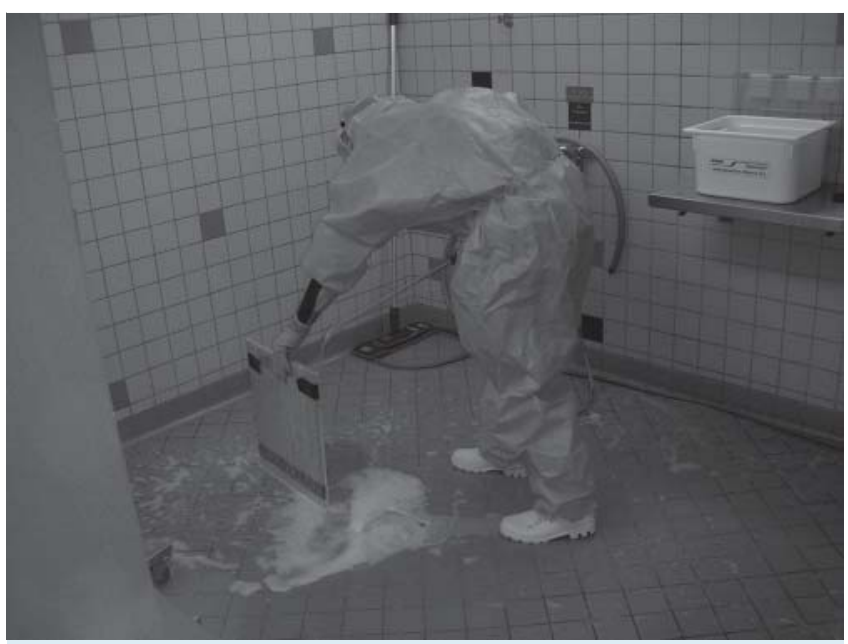

Fig. 5 Disinfection of the X-ray cassette in the decontamination chamber.

worsening of the patient's respiratory situation which necessitated intubation and artificial respiration on the same day ( $\bullet$ Fig. 7 ). By the 11 th treatment day the pulmonary hyperhydration was continuously increasing before a slight improvement was seen from the 13th to the 15th treatment day ( $\bullet$ Fig. 8) [9]. After a total of two weeks of intensive care treatment (day 20), the signs of congestion and the pleural effusions had regressed ( $\bullet$ Fig.9) to the point that the treating physicians were able to extubate the patient on day 22 . On day 27, X-ray showed complete recompensation ( $\bullet$ Fig. 10). In total, ten bedside X-rays were ordered, two primarily for position monitoring of intensive care materials and eight for follow-up. All chest X-rays were evaluated

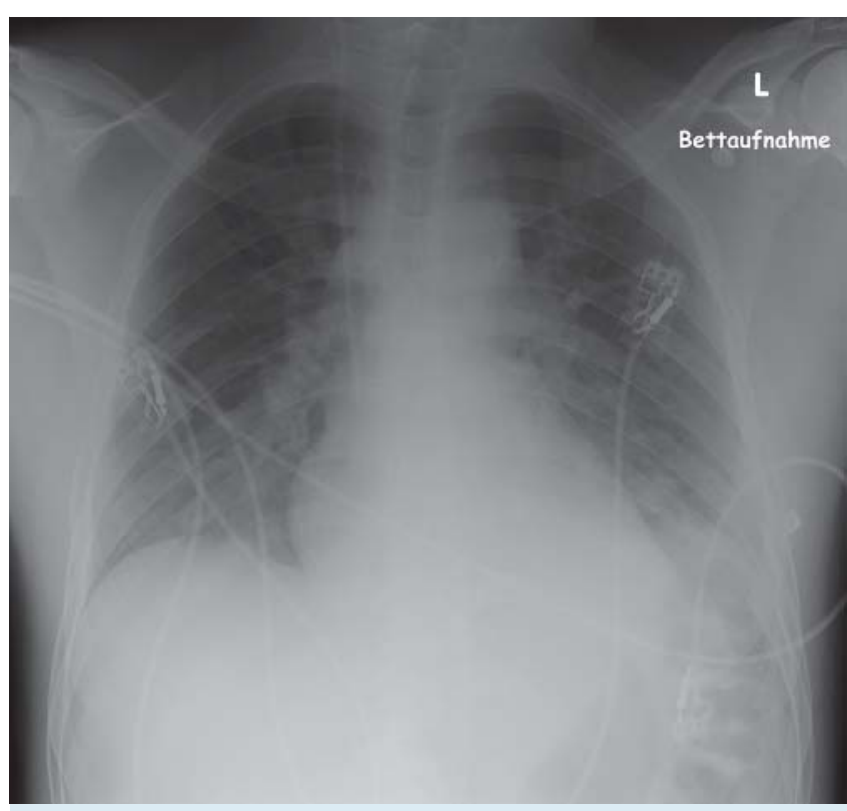

Fig. 6 Pulmonary edema and a loss of the normal contour of the diaphragm on the left consistent with pleural effusion was seen on the first X-ray image shortly after arrival of the patient (day 6 of the disease). Secondary finding: Elongated left flexure of the colon.

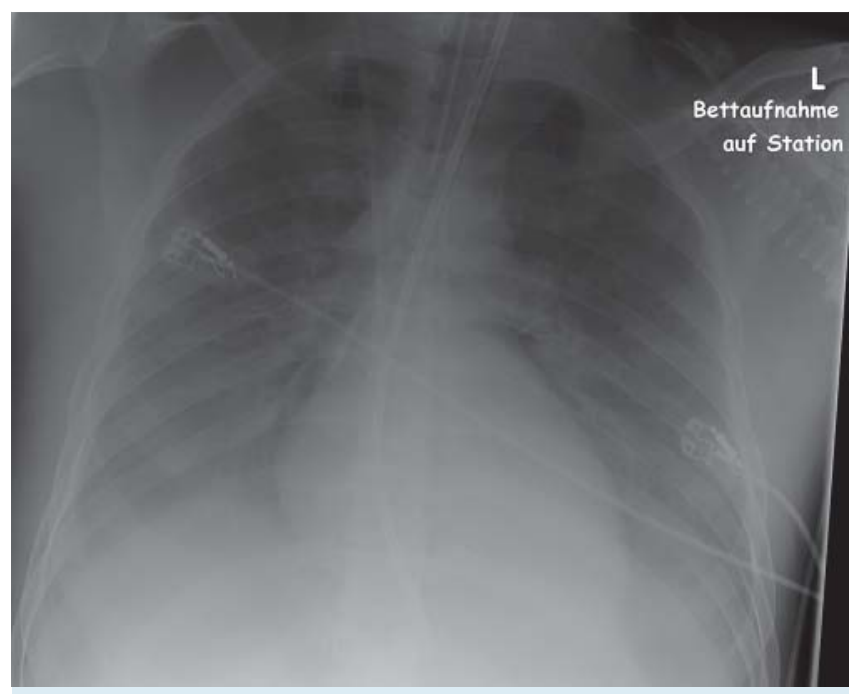

Fig. 7 On the 9th day of treatment, increasing pulmonary edema and pleural effusions were seen. Status after intubation.

by two independent radiologists according to the scoring system modified by Ware et al. [10] for evaluating the severity of pulmonary edema according to Murray et al. [11]. The point values correlate well with the extravascular lung 


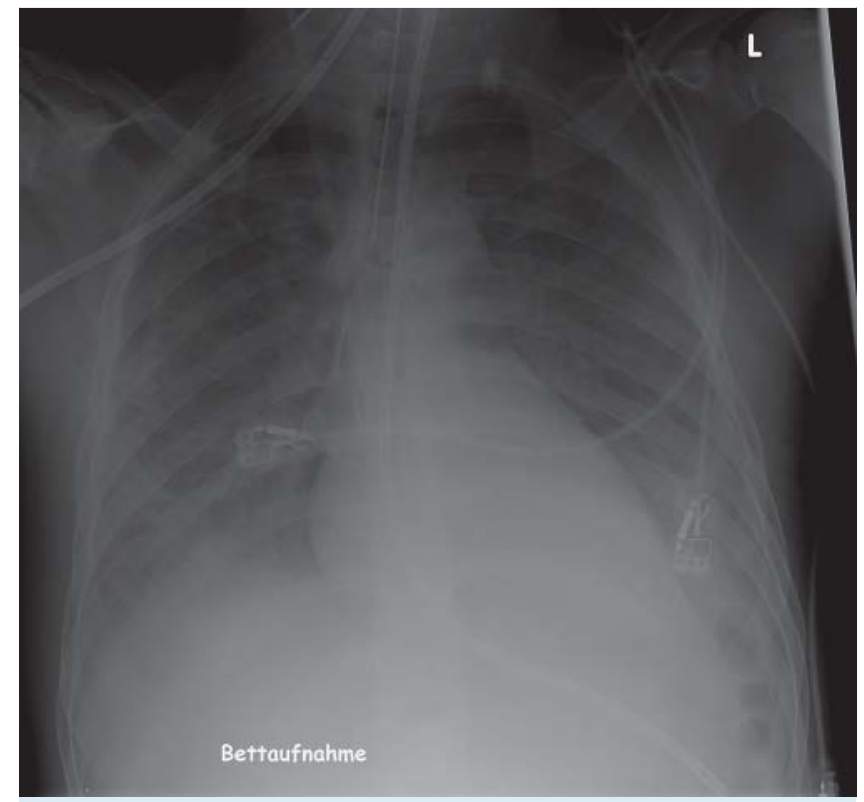

Fig. 8 Cardiopulmonary situation on day 15.

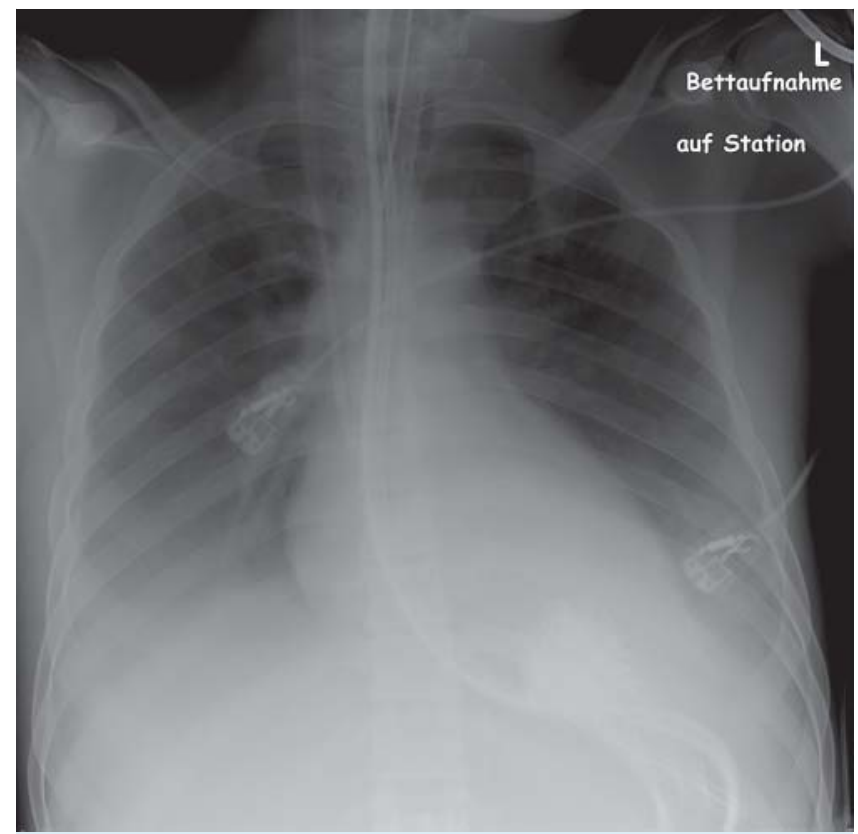

Fig. 9 On day 20 the pulmonary edema and the pleural effusions had regressed.

water index (EVLWI) determined with the help of the PiCCO technology (Pulsion Medical Systems, Munich, Germany) ( $\bullet$ Fig. 11). The EVLWI of the patient increased after intubation (day 9) from $12 \mathrm{ml} / \mathrm{kg}$ (normal value: $3-7 \mathrm{ml} / \mathrm{kg}$ ) within three days to $25 \mathrm{ml} / \mathrm{kg}$ (day 12) which underlines the peak of the capillary leak syndrome in accordance with the chest X-rays ( $\bullet$ Table 2 ).

Moreover, three additional abdominal X-rays were taken to evaluate small intestinal passage and to rule out free air. On the 11th day of the disease, significant slowing of the intestinal contrast agent transport ( $\bullet$ Fig. 12) into the proximal ileum was seen approx. 12 hours after initial contrast administration. Two days later (day 13), contrast-filled intes-

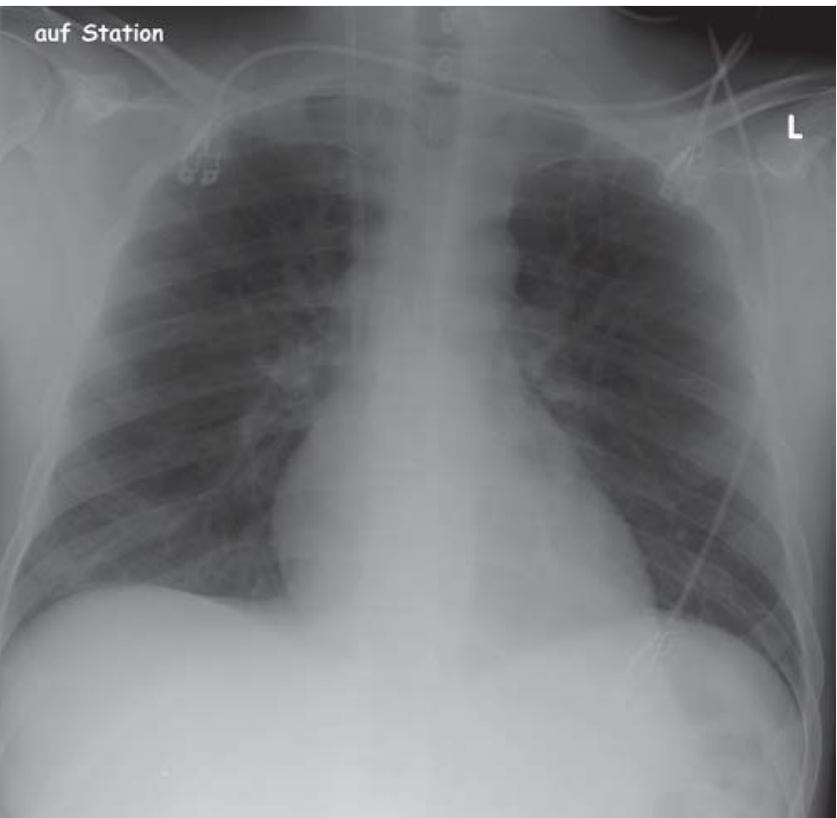

Fig. 10 On day 27 pleural effusions and pulmonary hyperhydration could no longer be detected on the X-ray taken with the patient in a lying position.

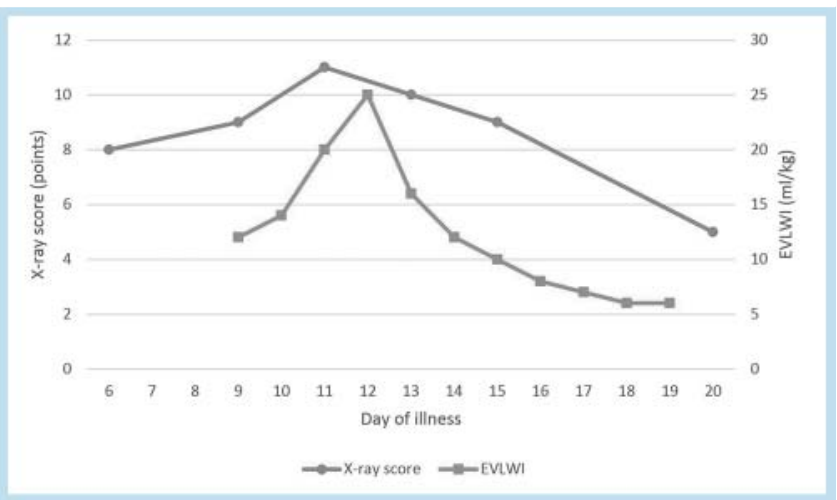

Fig. 11 This figure shows the clinical course during the treatment of the capillary leak syndrome. The $\mathrm{X}$-ray score shows regression of the pulmonary edema starting on the 12th day of the disease in correlation with the EVLWI.

Table 2 Clinical course during treatment of capillary leak syndrome. The $\mathrm{X}$-ray score according to Murray et al. and Ware et al. indicates the extent of the pulmonary edema $[10,11]$.

\begin{tabular}{|c|c|c|c|}
\hline $\begin{array}{l}\text { day of the } \\
\text { disease }\end{array}$ & X-ray score & EVLWI & $\begin{array}{l}\text { artificial } \\
\text { respiration }\end{array}$ \\
\hline 6 & 8 & - & no \\
\hline 9 & 9 & $12 \mathrm{ml} / \mathrm{kg}$ & yes \\
\hline 11 & 11 & $20 \mathrm{ml} / \mathrm{kg}$ & yes \\
\hline 13 & 10 & $16 \mathrm{ml} / \mathrm{kg}$ & yes \\
\hline 15 & 9 & $10 \mathrm{ml} / \mathrm{kg}$ & yes \\
\hline 20 & 5 & - & yes (to day 22 ) \\
\hline 27 & 0 & - & no \\
\hline
\end{tabular}

tinal loops could no longer be detected ( $\bullet$ Fig. 13). The final abdominal X-ray on day 20 was normal. 


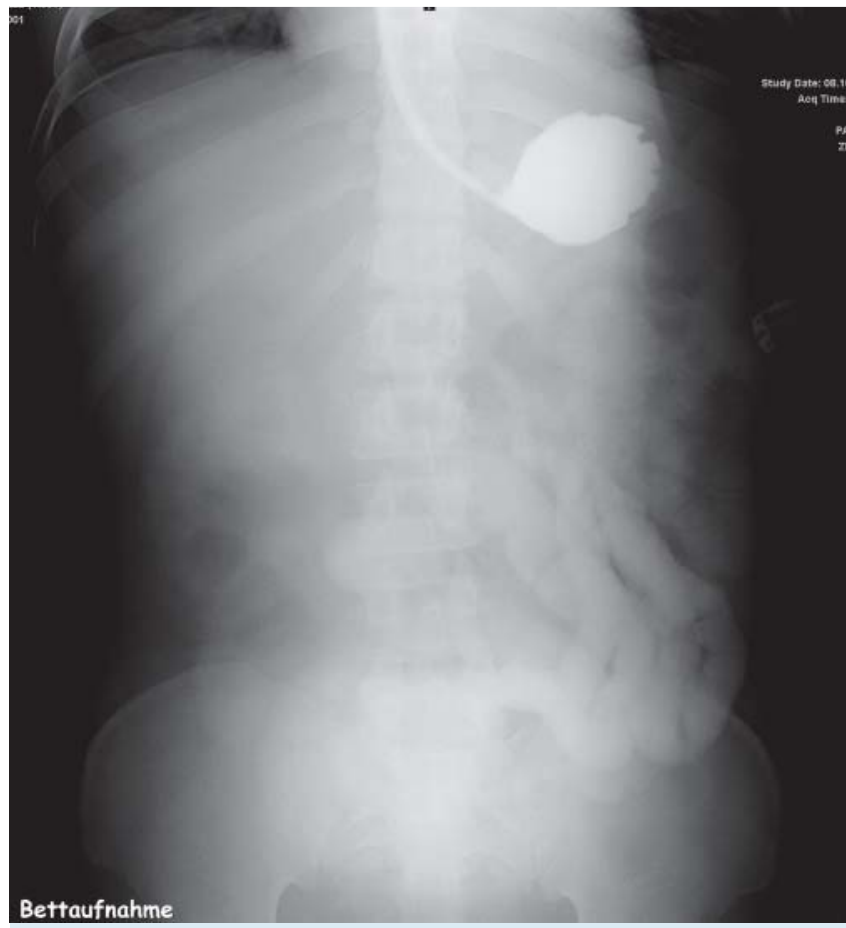

Fig. 12 Day 11: On the abdominal X-ray approx. 12 hours after initial contrast administration via the gastric tube, significantly slowed intestinal contrast agent transport into the proximal ileum was seen. Contrast enhancement of the gastric fundus during second contrast administration via the gastric tube. Minimal air filling of intestinal loops in projection onto the ileocecal pole.

\section{Summary}

$\nabla$

Chest X-rays are indispensable in the intensive care monitoring of Ebola patients due to the fluid shifts and they provide physicians with important information regarding cardiopulmonary status. In addition, it is helpful to quantify the degree of pulmonary edema with the help of the scoring system according to Murray and the EVLWI so that fluid shifts into the pulmonary interstitium can be diagnosed and treated early. Capillary leak syndrome is not only a pulmonary condition but can additionally result in liver and kidney insufficiency and thus in multiorgan failure. However, the EVLWI does not always correlate with the X-ray score as Lemson et al. showed in the treatment of children requiring intensive care [12]. However, in our case the measured values are largely in agreement.

By carefully complying with the guidelines regarding infection prevention for medical personnel and the materials being used, the risk of transmission can be virtually eliminated.

While an imaging plate system is currently used, a fully digital system would be desirable to avoid the need to transport the X-ray cassette and thus material from the isolation area. Such a system would allow wireless transmission to the central institute and thus faster evaluation of the X-ray images. However, the special isolation ward does not have the necessary technology because it is located in a separate building outside the actual hospital grounds and has a comparably low number of beds. Therefore, it would not be

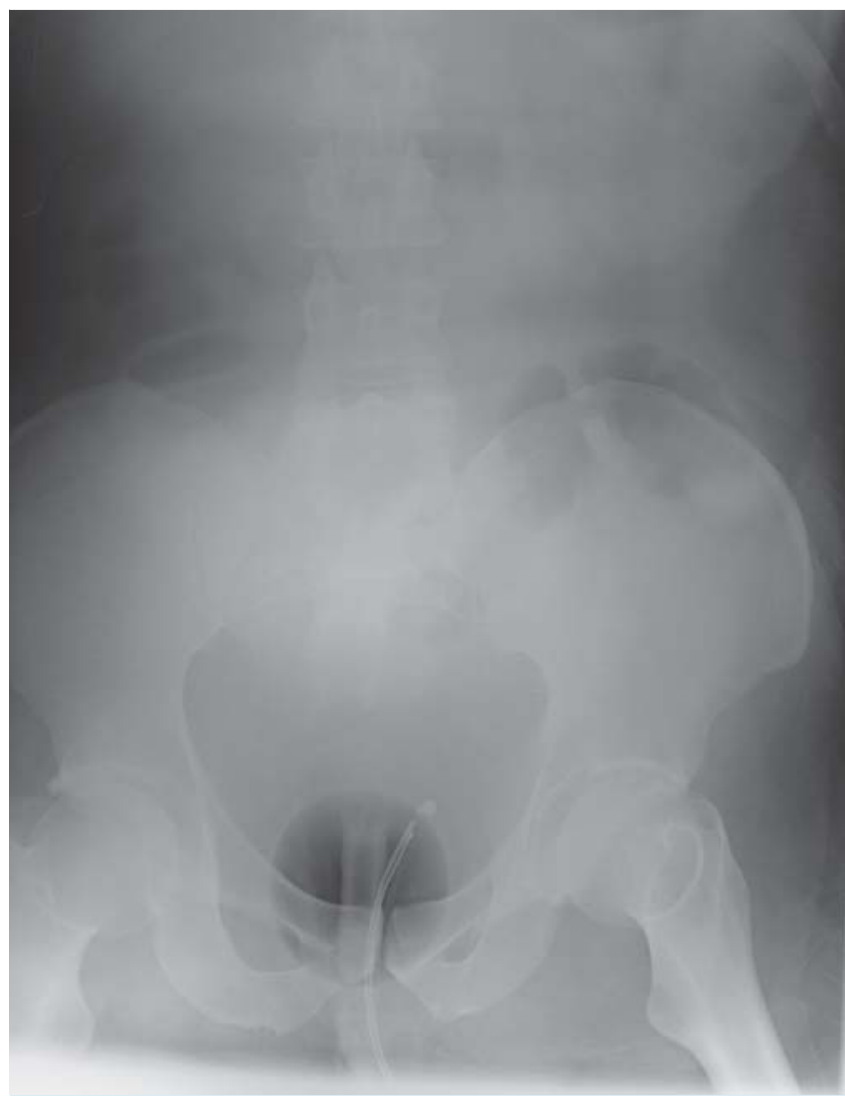

Fig. 13 On day 13 contrast-filled intestinal loops could no longer be detected. Only air-filled loops of the large intestine in the region of the transverse colon but no meteorism could be seen. Foreign material: Rectobag, urinary catheter.

cost-effective to purchase a digital detector and the corresponding console.

In general, surfaces in the patient's immediate vicinity are only rarely contaminated with the Ebola virus [13]. In the case of surface contamination, the Ebola virus can be infectious for up to six days [14]. The Robert Koch Institute (RKI) recommends disinfecting all instruments and devices that are or could be in direct contact with bodily fluids. The procedure for disinfecting large devices should be defined on an individual basis according to the recommendations of the RKI and depends on the probable extent of the contamination [8]. Therefore, regular disinfection by wiping when using the X-ray unit is sufficient $[15,16]$, typically once per day [17]. With respect to the reusability of the X-ray unit, formaldehyde fumigation is another possibility. This can be performed during the final room disinfection [8]. In the case of severe contamination (blood, vomit, feces), disposal of the unit should be considered.

\section{Literatur}

1 Okware SI, Omaswa FG, Zaramba S et al. An outbreak of Ebola in Uganda. Tropical medicine \& international health TM \& IH 2002; 7: 1068 1075

2 Baron RC, McCormick JB, Zubeir OA. Ebola virus disease in southern Sudan: hospital dissemination and intrafamilial spread. Bulletin of the World Health Organization 1983; 61: 997-1003 
3 MacNeil A, Farnon EC, Wamala J et al. Proportion of deaths and clinical features in Bundibugyo Ebola virus infection, Uganda. Emerging infectious diseases 2010; 16: 1969-1972

4 Roddy P, Howard N, Van Kerkhove MD et al. Clinical manifestations and case management of Ebola haemorrhagic fever caused by a newly identified virus strain, Bundibugyo, Uganda, 2007-2008. PloS one 2012; 7: e52986

5 Fisher-Hoch SP, Platt GS, Neild GH et al. Pathophysiology of shock and hemorrhage in a fulminating viral infection (Ebola). The Journal of infectious diseases 1985; 152: 887-894

6 Wolf T, Kreuels B, Schmiedel S et al. Ebolaviruserkrankung: Manifestationsformen der Infektion. Dtsch Arztebl 2014; 111: A 1856-A 1857

7 Feldmann H. Ebola - A Growing Threat? New England Journal of Medicine 2014; 371: 1375-1378

8 Robert-Koch-Institut. Maßnahmen zur Desinfektion nach Kontakt mit einem begründeten Ebolafieber-Verdachtsfall in Deutschland. http:// www.rki.de Stand: 1.12.2014

9 Wolf T, Kann G, Becker S et al. Severe Ebola virus disease with vascular leakage and multiorgan failure: treatment of a patient in intensive care. Lancet 2014; DOI: 10.1016/s0140-6736(14)62384-9

10 Ware $L B$, Neyrinck A, O'Neal HR et al. Comparison of chest radiograph scoring to lung weight as a quantitative index of pulmonary edema in organ donors. Clinical transplantation 2012; 26: 665-671
11 Murray JF, Matthay MA, Luce JM et al. An expanded definition of the adult respiratory distress syndrome. The American review of respiratory disease $1988 ; 138: 720-723$

12 Lemson J, van Die LE, Hemelaar AE et al. Extravascular lung water index measurement in critically ill children does not correlate with a chest $\mathrm{x}$ ray score of pulmonary edema. Critical care (London, England) 2010; 14: R105

13 Bausch DG, Towner JS, Dowell SF et al. Assessment of the risk of Ebola virus transmission from bodily fluids and fomites. The Journal of infectious diseases 2007; 196: S142-S147

14 Sagripanti JL, Rom AM, Holland LE. Persistence in darkness of virulent alphaviruses, Ebola virus, and Lassa virus deposited on solid surfaces. Archives of virology 2010; 155: 2035-2039

15 Kommission für Krankenhaushygiene und Infektionsprävention. Anforderungen an die Hygiene bei der Reinigung und Desinfektion von Flächen. Bundesgesundheitsbl 2004; 47: 51-61

16 Kommission für Krankenhaushygiene und Infektionsprävention. Anforderungen an die Hygiene bei der Aufbereitung von Medizinprodukten. Bundesgesundheitsbl 2012; 55: $1244-1310$

17 CDC. Interim Guidance for Environmental Infection Control in Hospitals for Ebola Virus. http://www.cdc.gov/vhf/ebola/hcp/environmental-infection-control-in-hospitals.html Stand: 14.11.2014 